\title{
TUBERCULOSIS AMONG CHILDREN IN SULAIMANI- CLINICAL PATTERN 2014 TO 2017
}

\author{
Khalid Hama Salih ${ }^{1}$
}

${ }^{1}$ College of Medicine, Department of Paediatrics, Paediatrics Teaching Hospital in Sulaimania, Iraq.

\section{ABSTRACT}

\section{BACKGROUND}

Tuberculosis (TB) is one of the most important global health problems. The prevalence of TB is high in the developing world. Tuberculosis in children still remains as one of the main causes of morbidity and mortality throughout the world, Knowledge about childhood tuberculosis (TB) in Kurdistan is limited. This study aimed to determine the proportion of tuberculosis in children living in Sulaimani, north of Iraq and its outcomes. This retrospective study was carried out to find the clinical pattern of pulmonary and extrapulmonary tuberculosis in children in Sulaimani city-Iraq.

\section{METHODS}

Medical records of 38 patients aged 0-15 years with childhood TB who were diagnosed in Chest and Respiratory Disease Center. The medical records were reviewed regarding clinical, demographic, outcome data and investigations.

\section{RESULTS}

A total of 38 medical records of childhood TB patients were included in this study. 24 (63\%) of them had extra pulmonary tuberculosis (EPTB) and 14 (37\%) had pulmonary tuberculosis (PTB). female patients were more in both; PTB 57.1\% and EPTB $54.1 \%$, compared to the male proportions which were $42.9 \%$ in PTB and $45.8 \%$ in EPTB with no statistically significant difference $(p<0.859)$ There was a significant difference between the incidence of PTB and the incidence of EPTB in deferent age groups. PTB was predominant in adolescent age, $78.6 \%$ of PTB patients were aged between 10-15 years. Vaccinated patient with BCG were less likely to get PTB (26.8\%) compared to $70.8 \%$ of EPTB who were vaccinated with BCG. $42.9 \%$ of PTB had a history of contact with a TB patient, and $8.3 \%$ of ЕРTB had TB contact history ( $\mathrm{p}$ value $=0.012$ ). In relation to the sex and address of TB patients there was no statistically significant difference between ЕРTB and PTB patients, a statistically significant difference was observed among PTB and EPTB regarding the results of TB skin test, GeneXpert test, ESR and chest $\mathrm{x}$ ray. The results of TB skin tests were positive in $42 \%$ of PTB whereas none of EPTB patients had a positive TB skin test ( $p$ value $<0.001$ ). GeneXpert test and chest $\mathrm{x}$ ray were more sensitive in detecting PTB than EPTB. 64.3\% of PTB cases had positive GeneXpert test results compared to 8.3\% of EPTB cases that had positive result ( $p$ value $<0.001$ ). Similarly, $85.7 \%$ of PTB and $12.5 \%$ of EPTB had positive chest $x$ ray results ( $p$ value $<0.001$ ). PTB obviously had a higher ESR test results, 7.1\% of this group had ESR less than 50, and 50\% of them had ESR result between 50 and 100 and $43.9 \%$ had ESR more than 100, in contrast EPTB group ESR results for same classification were 50\%, 41.7\% and 8.3\% respectively ( $\mathrm{p}<0.006$; Table 2). Nevertheless, tissue biopsy test results in the two groups were not significantly different $(\mathrm{p}<0.052)$, but EPTB was more likely to have the positive result $95.8 \%$ versus $71.4 \%$ of PTB had positive results.

\section{CONCLUSIONS}

Majority of the patients had EPTB and pleural tuberculosis was the most common among patients with EPTB. Female patients were more common in both EPTB and PTB cases. Vaccinated child was less susceptible to pulmonary TB than EPTB, both PTB and EPTB were more common among crowded families.

\section{KEY WORDS}

Tuberculosis, Child, Epidemiology, Clinical Pattern

HOW TO CITE THIS ARTICLE: Salih KH. Tuberculosis among children in Sulaimani- clinical pattern 2014 to 2017. J. Evolution Med. Dent. Sci. 2019;8 (22):1800-1803, DOI: 10.14260/jemds/2019/395

\section{BACKGROUND}

In its 2017 report, the WHO estimates that, of the 10.4 million incident cases of TB in 2016, approximately one million occurred among children under age 15 of the 10.4 million incident cases of TB reported in 2016, 6.9 percent were in children with an equal number of males and females. (1)

In 2017, the WHO and colleagues estimated that there were 239,000 paediatric deaths due to TB $(39,000$ occurring

'Financial or Other Competing Interest': None.

Submission 23-03-2019, Peer Review 18-05-2019,

Acceptance 23-05-2019, Published 03-06-2019.

Corresponding Author:

Dr. Khalid Hama Salih,

College of Medicine, Paediatrics Department,

Paediatrics Teaching Hospital in Sulaimania,

Iraq.

E-mail: khalidh976@yahoo.com

DOI: $10.14260 /$ jemds $/ 2019 / 395$

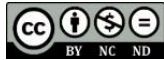

in HIV-infected children), approximately 80 percent of these deaths occurred in children under age five. (2) Although tuberculosis is primarily the disease of affecting the lungs (Pulmonary Tuberculosis; PTB), it may have various manifestations and can affect many sites such as lymph nodes, central nervous system, bones, and gastrointestinal tract which is known as Extra-pulmonary tuberculosis (EPTB). (3,4) Tuberculosis (TB) in children is often diagnosed clinically. Because pulmonary $\mathrm{TB}$ in children typically presents with paucibacillary, non-cavitary pulmonary disease, bacteriologic confirmation is achievable in less than 50 percent of children and 75 percent of infants; in such cases, pulmonary TB is diagnosed by other clinical criteria, (5) For diagnosis of extrapulmonary TB, specimens for culture should be collected from any site where infection is suspected. Each specimen should be cultured regardless of acid-fast bacilli (AFB) smear results. (5) 
A diagnosis of TB (Pulmonary or extrapulmonary) in a child is often based on the presence of the classic triad: 1 . recent close contact with an infectious case, 2 . a positive tuberculin skin test (TST) or interferon-gamma release assay (IGRA), and 3. suggestive findings on chest radiograph or physical examination. (6)

In this regard, the present retrospective study was aimed at finding the clinical pattern of pulmonary and extrapulmonary tuberculosis in children in Sulaimani cityIraq.

\section{METHODS}

The present retrospective descriptive study was carried out at Chest and respiratory disease center in Sulaimani district at Kurdistan region of Iraq. The medical records of childhood TB patients aged 0 to 15 years for four years between $1^{\text {st }}$ January 2014 and 31st December 2017 were reviewed. All patients with confirmed diagnosis of TB infection were included. A predesigned questionnaire was used to retrieve information of patients records which included; demographic data (Age, sex, residency, crowding index etc.), medical history (Vaccination, family history of TB, history of contact), investigation results (TB skin test, GeneXpert test, chest Xray, ESR and tissue biopsy), prognosis outcome (Recovery, under treatment and death). The data coded and added to a Microsoft excel spread sheet, IBM-SPSS software version 22 was used for data analysis. Categorical variables were expressed via frequencies and percentages, and for comparison between categorical variables, to assess the significant association between observed proportions, the Chi square test and Fisher exact test were used (a p value $<0.05$ was considered as a statistically significant cut-off of the tests).

\section{RESULTS}

A total of 38 medical records of childhood TB patients were included in this study 24 (63\%) of them had extra pulmonary tuberculosis (EPTB) and 14 (37\%) had Pulmonary tuberculosis (PTB). All enrolled patients were Iraqi living in Sulaimani province. A higher proportion of female patients observed in both TB infections; PTB 57.1\% and ЕРTB 54.1\%, compared to the male proportions which were $42.9 \%$ in PTB and $45.8 \%$ in EPTB with no statistically significant difference $(\mathrm{P}<0.859)$ Table 1.

There was a significant difference between the incidence of PTB and the incidence of EPTB in different age groups. PTB was predominant in adolescent age, $11(78.6 \%)$ of PTB patients aged between $10-15$ years, and $2(14.3 \%)$ of them were less than 5 years old. While the EPTB was more prevalent in under-five children by 15 (62.5\%) (p value $<0.002)$ Table 1 . Vaccinated patient with BCG were less likely to get PTB $4(26.8 \%)$ compared to $17(70.8 \%)$ of EPTB which were vaccinated with BCG. 6 (42.9\%) of PTB had a history of contact with a TB patient, and $2(8.3 \%)$ of EPTB had TB contact history ( $\mathrm{p}$ value $=0.012$ ).

In relation to the sex and address of TB patients there was no statistically significant difference between EPTB and РTB patients, Table 1 .

\begin{tabular}{|c|c|c|c|}
\hline $\begin{array}{c}\text { Socio-Demographic } \\
\text { Data }\end{array}$ & $\begin{array}{c}\text { Pulmonary } \\
\text { No. (\%) }\end{array}$ & \begin{tabular}{|c|} 
Extra-Pulmonary \\
No. (\%)
\end{tabular} & (p-Value) \\
\hline \multicolumn{4}{|c|}{ Age } \\
\hline Less than 5 years & $2(14.3)$ & $15(62.5)$ & \multirow{3}{*}{$* 0.002$} \\
\hline $5-10$ years & $1(7.1)$ & 4 (16.7) & \\
\hline $10-15$ years & $11(78.6)$ & $5(20.8)$ & \\
\hline \multicolumn{4}{|c|}{ Gender } \\
\hline Male & $6(42.9)$ & $11(45.8)$ & \multirow[b]{2}{*}{$\# 0.859$} \\
\hline Female & $8(57.1)$ & $13(54.2)$ & \\
\hline \multicolumn{4}{|c|}{ Address } \\
\hline Inside city & $7(50)$ & $11(45.8)$ & \multirow[b]{2}{*}{$\# 0.804$} \\
\hline Outside city & $7(50)$ & $13(54.2)$ & \\
\hline \multicolumn{4}{|c|}{ Crowd Index } \\
\hline Index $<4$ & $0(0.0)$ & $9(37.5)$ & \multirow[b]{2}{*}{ *0.009 } \\
\hline Index $>4$ & $14(100)$ & $15(62.5)$ & \\
\hline \multicolumn{4}{|c|}{ BCG } \\
\hline Vaccinated & $4(28.6)$ & $17(70.8)$ & \multirow{3}{*}{${ }^{*} 0.037$} \\
\hline Un-vaccinated & $2(14.3)$ & $2(8.4)$ & \\
\hline Un known & $8(57.1)$ & $5(20.8)$ & \\
\hline \multicolumn{4}{|c|}{ FHTB } \\
\hline Parent & $0(0.0)$ & $1(4.2)$ & \multirow{4}{*}{ *0.010 } \\
\hline Sibling & $5(35.7)$ & $1(4.2)$ & \\
\hline Grand parent & $1(7.1)$ & $0(0.0)$ & \\
\hline No & $8(57.2)$ & 22 (91.6) & \\
\hline \multicolumn{4}{|c|}{ History Contact } \\
\hline Yes & $6(42.9)$ & $2(8.3)$ & \multirow[b]{2}{*}{${ }^{*} 0.012$} \\
\hline No & $8(57.1)$ & $22(91.7)$ & \\
\hline \multicolumn{4}{|c|}{$\begin{array}{l}\text { Table 1. Socio-Demographic Distribution of Pulmonary and } \\
\text { Extra-Pulmonary TB }\end{array}$} \\
\hline \multicolumn{4}{|c|}{$\begin{array}{l}\text { *p value calculated using Fisher's Exact Test. } \\
\text { \# p value calculated using Pearson Chi-Square. }\end{array}$} \\
\hline
\end{tabular}

\begin{tabular}{|c|c|c|c|}
\hline Investigation Data & $\begin{array}{c}\text { Pulmonary } \\
\text { No. (\%) }\end{array}$ & \begin{tabular}{|c|} 
Extra-Pulmonary \\
No. (\%)
\end{tabular} & (p-Value) \\
\hline \multicolumn{4}{|c|}{ TB Skin Test } \\
\hline Positive & $6(42.9)$ & $0(0.0)$ & \multirow[b]{2}{*}{$* 0.001$} \\
\hline Negative & $8(57.1)$ & $24(100)$ & \\
\hline \multicolumn{4}{|c|}{ GeneXpert Test } \\
\hline Positive & $9(64.3)$ & $2(8.3)$ & \multirow[b]{2}{*}{$* 0.001$} \\
\hline Negative & 5 (35.7) & $22(91.7)$ & \\
\hline \multicolumn{4}{|c|}{ Chest X-ray } \\
\hline Positive & $12(85.7)$ & $3(12.5)$ & \multirow[b]{2}{*}{ * 0.001} \\
\hline Negative & $2(14.3)$ & $21(87.5)$ & \\
\hline \multicolumn{4}{|c|}{ ESR } \\
\hline$<50$ & $1(7.1)$ & $12(50)$ & \multirow[b]{3}{*}{$* 0.006$} \\
\hline $50-100$ & $7(50)$ & $10(41.7)$ & \\
\hline$>100$ & $6(42.9)$ & $2(8.3)$ & \\
\hline \multicolumn{4}{|c|}{ Tissue Biopsy } \\
\hline Positive & $10(71.4)$ & 23 (95.8) & \multirow[b]{2}{*}{$* 0.052$} \\
\hline Negative & $4(28.6)$ & $1(4.2)$ & \\
\hline \multicolumn{4}{|c|}{$\begin{array}{c}\text { Table 2. Pulmonary and Extra-Pulmonary TB } \\
\text { Investigation Results }\end{array}$} \\
\hline \multicolumn{4}{|c|}{$\begin{array}{l}{ }^{*} \text { p value calculated using Fisher's Exact Test } \\
\text { \# p value calculated using Pearson Chi-Square }\end{array}$} \\
\hline
\end{tabular}

\begin{tabular}{|c|c|c|c|}
\hline Outcome & $\begin{array}{c}\text { Pulmonary } \\
\text { No. (\%) }\end{array}$ & $\begin{array}{c}\text { Extra- } \\
\text { Pulmonary } \\
\text { No. (\%) }\end{array}$ & $\begin{array}{c}\text { (p- } \\
\text { Value) }\end{array}$ \\
\hline Recover & $9(64.3)$ & $15(62.5)$ & \multirow{2}{*}{$* 0.585$} \\
\hline Still treat & $3(21.4)$ & $8(33.3)$ & $1(4.2)$ \\
\cline { 1 - 3 } Die & $2(14.3)$ & \multirow{2}{*}{ Table 3. The Relationship Between Pulmonary and } \\
\multicolumn{2}{|c|}{ Extra-Pulmonary TB According to The Prognosis } \\
\hline
\end{tabular}




\begin{tabular}{|c|c|c|c|}
\hline Year & $\begin{array}{l}\text { Pulmonary } \\
\text { No. (\%) }\end{array}$ & $\begin{array}{l}\text { Extra-Pulmonary } \\
\text { No. (\%) }\end{array}$ & (p-Value) \\
\hline 2014 & $2(14.3)$ & $2(8.3)$ & \multirow{4}{*}{$* 0.502$} \\
\hline 2015 & $7(50.0)$ & 7 (29.2) & \\
\hline 2016 & $3(21.4)$ & $10(41.7)$ & \\
\hline 2017 & $2(14.3)$ & $5(20.8)$ & \\
\hline \multicolumn{4}{|c|}{$\begin{array}{c}\text { Table 4. The Relationship Between Pulmonary and } \\
\text { Extra-Pulmonary TB According to The Year }\end{array}$} \\
\hline \multicolumn{4}{|c|}{$\begin{array}{l}\text { *p value calculated using Fisher's Exact Test. } \\
\text { \# p value calculated using Pearson Chi-Square. }\end{array}$} \\
\hline
\end{tabular}

Table 2 shows the results of various investigations that were used to detect the TB infections, a statistically significant difference was observed among PTB and EPTB regarding the results of TB skintest, GeneXpert test, ESR and chest x-ray. The results of TB skin tests were positive in 6 (42\%) of PTB whereas none of EPTB patients had a positive TB skin test ( $\mathrm{p}$ value $<0.001$ ). GeneXpert test and chest $\mathrm{x}$ ray were more sensitive to detect PTB than EPTB. 9 (64.3\%) of PTB cases had positive GeneXpert test results compared to 2 (8.3\%) of EPTB cases that had positive result ( $p$ value $<0.001)$.Similarly, $12(85.7 \%)$ of PTB and $3(12.5 \%)$ of EPTB had positive chest $x$-ray results ( $p$ value $<0.001$ ).

PTB obviously had a higher ESR test results, 1 (7.1\%) of this group had ESR less than 50 , and $7(50 \%)$ of them had ESR result between 50 and 100 and 6 (43.9\%) had ESR more than 100, in contrast EPTB group ESR results for same classification were 12 (50\%), 10 (41.7\%) and $2(8.3 \%)$ respectively $(\mathrm{P}<0.006$; Table 2$)$. Nevertheless, tissue biopsy test results in the two groups were not significantly different $(\mathrm{p}<0.052)$, but EPTB was more likely to have the positive result $23(95.8 \%)$ versus 10 (71.4\%) of PTB had positive results.

The outcomes in both types of TB were nearly the same, more than $60 \%$ of patients were cured and between 4 to $15 \%$ died $(\mathrm{p}$ value $=585)$ Table 3 .

No statistically significant difference has been noticed in the yearly occurrence of both types of the disease in 2014 to 2017 (Table 4).

\section{DISCUSSION}

This study conducted on 38 children with tuberculosis at Chest and respiratory disease center in Sulaimani district at Kurdistan region of Iraq from $1^{\text {st }}$ Jan 2014 to 31st of December 2017, were 24 children had extra-pulmonary tuberculosis (EPTB) and 14 had pulmonary tuberculosis (PTB).

One of the main risk factor to development and progression of TB is age. (7) In the current study, TB among children at lower than 5 years old was highest compared to older groups. (8) EPTB were highest among children were at low ages (Less than 5 years old) compare to PTB children were most among children at higher ages (10-15 years) with significant relation between PTB and EPTB according to children age groups, same results observed in other studies (911) and other studies show that EPTB is higher in older adolescents compared to children. (12) Female children were more at risk to acquire TB than male children and female children were highest in both EPTB and PTB cases compare to male children with non-significant relationship. $(9,13,14)$ However, other studies reported that male children more to
EPTB but still it is not a significant relationship. (12,15) This differences among studies might relate to geo-demographic or type of sample size or collection method of the study. Majority of participate children were from rural areas, PTB was equal in both areas and EPTB were more from rural areas than urban with no significant relation. (16)

Vaccinated with BCG were higher among ESTB compare to PTB with a significant difference between the two groups. We found the same result in Kumar's (15) study but with nonsignificant relation and studies suggested that because of BCG cause complex cytokine profiles in both CD4+ and CD8+ T cells. (17) Children with BCG cause bias in biomarkers and skin TB test to detect between healthy and TB children. (18)

Majority of children participated in this study had negative contact and family history with TB for both categories. (13) This could be related to children in our society children at low ages only in continuous contact with the parents in state of in care centers. (19) Family history and previous contact were more among PTB compare to EPTB children with a non-significant relationship in our study and we found same results in other studies, were negative contact more among EPTB. $(9,20)$ The Sreeramareddy's study found that history contact with TB significantly associated with PTB.

Majority of TB skin test were negatives for both groups, it might be related to those majority children in this region are vaccinated with BCG that make skin test limited benefit to diagnosis TB, some studies suggest that TB skin test is limited to declare difference between active and latent TB among children compared to adults and TB skin test among young children and infants not well studied. (10,21) EPTB skin tests were negative while $42.9 \%$ of PTB were positive cases with significant relation between skin test and two groups, same results observed in other studies and there are studies concluded smaller TB skin test in diameter among EPTB compare PTB children. (11) GeneXpert Mycobacterium tuberculosis/resistance to rifampin (MTB/RIF) assay results in our study show increase of test sensitivity among rapid tests for detection TB for both PTB and ЕРTB. $(22,23)$

An increase of WBC against active TB including ESR and PCR are bio-markers to detect TB. $(15,24)$ However, in our study we found the opposite result and same as Devrim's study in Turkey (13) also ESR were lower among EPTB than PTB in both studies. Tissue biopsy was highly sensitive biomarker test to detect ЕРТВ compare to other tests and it was higher than PTB. $(15,25)$

Chest $\mathrm{x}$-ray test is primary radiologist test used to diagnosis patients suspect of TB after two or more weeks of a cough and chest pain, our results indicated that chest X-ray was highly positive in pulmonary, as one of the main tools for diagnosis of pulmonary TB is x-ray finding as may cause a change in lung parenchyma and appear on chest X-ray with time, and this is consistent with other studies. (26)

Outcome of most TB children participated in this study were recover and recover rate among EPTB children were more compare to PTB children with non-significant relationship, this opposite to Garcia study found that EPTB children more risk to TB complications and death rate were higher compare PTB children with significant relationship. (11) 


\section{CONCLUSIONS}

Majority of the patients had EPTB and pleural tuberculosis was the most common among patients with EPTB. Female patients were more common in both EPTB and PTB cases. Vaccinated child was less susceptible to pulmonary TB than EPTB, both PTB and EPTB were more common among crowded families.

\section{REFERENCES}

[1] Global tuberculosis report 2018. Geneva: World Health Organization, 2018. Licence: CC BY-NC-SA 3.0 IGO. www.who.int/tb/publications/global_report/en/

[2] Dodd PJ, Yuen CM, Sismanidis C, et al. The global burden of tuberculosis mortality in children: a mathematical modelling study. The Lancet Global Health 2017;5(9):e898-e906.

[3] Carrol ED, Clark JE, Cant AJ. Non-pulmonary tuberculosis. Paediatric Respiratory Reviews 2001;2(2):113-9.

[4] Golden MP, Vikram HR. Extrapulmonary tuberculosis: an overview. American Family Physician 2005;72(9):1761-8.

[5] Kimberlin DW, Brady MT, Jackson MA, et al. Red Book, 30th edn (2015). 2015 Report of the Committee on Infectious Diseases: Am Acad Pediatrics 2015.

[6] Organization WH. Guidance for national tuberculosis programmes on the management of tuberculosis in children: World Health Organization, 2014.

[7] Black RE, Sivitz LB, Mitchell AE. Gulf War and Health: Infectious Diseases. Vol. 5. National Academies Press 2006.

[8] Buonsenso D, Lancella L, Delogu G, et al. A twenty-year retrospective study of pediatric tuberculosis in two tertiary hospitals in Rome. The Pediatric Infectious Disease Journal 2012;31(10):1022-6.

[9] Lotfian F, Bolursaz MR, Tabarsi P, et al. Comparison between pulmonary and extrapulmonary tuberculosis in adolescents. Archives of Pediatric Infectious Diseases 2017;5(3):e57253.

[10] Cruz AT, Starke JR. Pediatric tuberculosis. Pediatrics in Review 2010;31(1):13-26.

[11] Santiago-García B, Blázquez-Gamero D, BaqueroArtigao F, et al. Pediatric extrapulmonary tuberculosis: clinical spectrum, risk factors and diagnostic challenges in a low prevalence region. The Pediatric Infectious Disease Journal 2016;35(11):1175-81.

[12] Sepulveda EVF, Yunda LFI, Herrera KCM, et al. Extrapulmonary tuberculosis in Colombian children: epidemiological and clinical data in a reference hospital. International Journal of Mycobacteriology 2017;6(2):132-7.

[13] Devrim I, Aktürk H, Bayram N, et al. Differences between pediatric extra-pulmonary and pulmonary tuberculosis: a warning sign for the future. Mediterranean Journal of Hematology and Infectious Diseases 2014;6(1):e2014058.
[14] Fader T, Parks J, Khan NU, et al. Extrapulmonary tuberculosis in Kabul, Afghanistan: a hospital-based retrospective review. International Journal of Infectious Diseases 2010;14(2):e102-e10.

[15] Kumar NP, Anuradha R, Andrade BB, et al. Circulating biomarkers of pulmonary and extrapulmonary tuberculosis in children. Clinical and Vaccine Immunology 2013;20(5):704-11.

[16] Gaur PS, Suryakant, Bhaskar R, et al. Incidence and clinical profiles of pulmonary and extra-pulmonary tuberculosis patients in North Indian population: a hospital based retrospective study. IJRDPLS 2017;6(5):2773-8.

[17] Soares AP, Scriba TJ, Joseph S, et al. Bacillus CalmetteGuerin vaccination of human newborns induces T cells with complex cytokine and phenotypic profiles. The Journal of Immunology 2008;180(5):3569-77.

[18] Seddon JA, Paton J, Nademi Z, et al. The impact of BCG vaccination on tuberculin skin test responses in children is age dependent: evidence to be considered when screening children for tuberculosis infection. Thorax 2016;71(10):932-9.

[19] Batra S, Ayaz A, Murtaza A, et al. Childhood tuberculosis in household contacts of newly diagnosed TB patients. PLoS One 2012;7(7):e40880.

[20] Scott LE, Beylis N, Nicol M, et al. The diagnostic accuracy of Xpert MTB/RIF on extra pulmonary tuberculosis specimens: establishing a laboratory testing algorithm for South Africa. Journal of Clinical Microbiology J Clin Microbiol 2014;52(6):1818-23.

[21] Soysal A, Turel O, Toprak D, et al. Comparison of positive tuberculin skin test with an interferongamma-based assay in unexposed children. Japanese Journal of Infectious Diseases 2008;61(3):192-5.

[22] Pehme L, Hollo V, Rahu M, et al. Tuberculosis during fundamental societal changes in Estonia with special reference to extrapulmonary manifestations. Chest 2005;127(4):1289-95.

[23] Vadwai V, Boehme C, Nabeta P, et al. Xpert MTB/RIF, a new pillar in the diagnosis of extrapulmonary tuberculosis? Journal of Clinical Microbiology J Clin Microbiol 2011;49(7):2540-5.

[24] Wilson D, Badri M, Maartens G. Performance of serum C-reactive protein as a screening test for smearnegative tuberculosis in an ambulatory high HIV prevalence population. PLoS One 2011;6(1):e15248.

[25] Vivar DEP, Cruz YJT, Villasana JEM. Diagnosis of extrapulmonary tuberculosis: Systematic analysis of literature and study of seven cases in the cervicofacial region. Revista Odontológica Mexicana 2016;20(4):258-64.

[26] Ryu YJ. Diagnosis of pulmonary tuberculosis: recent advances and diagnostic algorithms. Tuberculosis and Respiratory Diseases (Seoul) 2015;78(2):64-71. 
